\title{
Effects of Iron Deficiency and Its Indicators on Lymphocyte Subsets: A Study at King Fahd Hospital of the University, Saudi Arabia
}

\author{
Lolwa AIRajeh $\mathbb{D}^{\prime}$, Amr Zaher $\mathbb{D I}^{\prime}$, Amal alghamdi $\mathbb{D}^{2}$, Rasha Alsheikh², Osama AlSultan ${ }^{3}$ \\ 'Department of Pathology, College of Medicine, Imam Abdulrahman University, Dammam, Saudi Arabia; ${ }^{2}$ Family and Community Medicine \\ Department, College of Medicine, Imam Abdulrahman University, Dammam, Saudi Arabia; ${ }^{3}$ Internal Medicine Department, King Fahd University \\ Hospital, Al Khobar, Saudi Arabia \\ Correspondence: Lolwa AIRajeh, Email Irajeh@iau.edu.sa
}

\begin{abstract}
Background: Iron deficiency plays an important role in our body's immunity. Several studies have shown that it is frequently associated with infections.

Objective: This study aimed to discover the effect of iron deficiency on immunity by demonstrating changes occurring in lymphocyte subsets among patients with an established diagnosis of iron deficiency.

Methods: A total of 64 iron-deficient patients and 19 healthy controls were included. Complete blood counts, serum iron, ferritin, and total iron-binding capacity were assessed. Lymphocyte subsets were evaluated by flow cytometry.

Results: Among iron-deficient patients, the anemic ones $(\mathrm{Hb} \leq 11 \mathrm{~g} / \mathrm{dL})$ showed significantly lower absolute lymphocyte counts $(p=0.013)$, lower relative and absolute NK-cell counts ( $p=0.025$ and $p=0.003$, respectively), higher relative T-cell and CD4 ${ }^{+}$ cell counts $\left(\mathrm{p}=0.026\right.$ and $\mathrm{p}=0.002$, respectively). B cells and $\mathrm{CD} 8^{+} \mathrm{T}$ cells were not affected by any iron-deficiency indicators. Irondeficient anemia patients showed a three- to fourfold increase in risk of having recurrent infections.

Conclusion: Iron deficiency has an obvious effect on lymphocyte subsets. Changes in lymphocyte subsets started mainly in response to decreased hemoglobin, rather than decreased ferritin and/or iron. Synchronously decreased hemoglobin and increased total ironbinding capacity led to absolute decreases in total lymphocytes, mainly NK cells, and relative increases in T cells, mainly the helper ones. Monitoring changes in lymphocyte subsets may be helpful in identifying patients at risk of recurrent infections.
\end{abstract}

Keywords: iron deficiency, lymphocyte subsets, immunity, flow cytometry

\section{Introduction}

Deficiencies in various vitamins and minerals can influence the human body by different mechanisms. Although iron is the most abundant metal on earth, iron deficiency is common clinical condition seen almost daily in clinical practice. It has impacts on both physical and mental development, as well as work performance, especially in children and premenopausal women. Beside its role in red blood-cell formation, iron plays an important role in our defense mechanism in different ways. Worldwide, several observational studies have shown that iron deficiency is frequently associated with increased susceptibility to infection. ${ }^{1-3}$ Omara and Blakely showed that there was impaired lymphocyte proliferation in rats fed iron-depleted food compared to those fed a regular diet. They also showed that iron deficiency can cause thymic atrophy in animals. ${ }^{4}$ Sejas et al observed that children with iron-deficiency anemia had significantly lower lymphocyte counts than controls. ${ }^{5}$ Other studies have been done on pregnant females with iron-deficiency anemia and found decreased T-cell counts and CD4:CD8 ratios. ${ }^{6,7}$ There is a complex yet not fully understand relationship between iron status and immunofunction, and there have not been enough studies to indicate which indicator of iron deficiency (eg, ferritin level, hemoglobin level, serum-iron level, and total iron-binding capacity [TIBC]) initiates these changes in lymphocyte subsets. ${ }^{8}$ Also, a majority of studies have focused mainly on pediatric age-groups rather than adult cases. The objective of this study was to highlight and expand knowledge about the effect of iron deficiency on 
immunity by demonstrating any changes that might occur in patterns of lymphocyte subsets among patients with an established diagnosis of iron-deficiency anemia and discover which indicator(s) initiate these.

\section{Methods}

This study was conducted at King Fahd University Hospital, Al-Khobar, Saudi Arabia from July 2018 to July 2019. All inpatients/outpatients of all nationalities presenting during this period and fulfilling our inclusion criteria for possible iron deficiency were included. The study was approved by the institutional review board (IRB-2019-047-Med) and research ethics committee of Imam Abdulrahman University, and was conducted in accordance with the Declaration of Helsinki. Informed consent was obtained from both patients and controls. For participants aged $<18$ years, informed consent was obtained from a parent or legal guardian. All data were kept confidential and used for research purposes only.

\section{Inclusion Criteria for Patients}

All male and female patients aged $>14$ years clinically indicated and laboratory-proven to be iron-deficient (ie, with microcytic hypochromic red blood cells, MCV $<80 \mathrm{fL}$, and serum ferritin $<20 \mathrm{ng} / \mathrm{mL}$ ) were included. ${ }^{9,10}$ All patients needed to be free of active ongoing infection or parasitic infestation. Patients had to have no history of autoimmune diseases, malignancies, or other nutritional deficiencies, immunosuppressant drug intake, receipt of radiotherapy or chemotherapy treatment, and no history of hematinic intake in the preceding 3 months. According to the World Health Organization definition of anemia (hemoglobin $<12 \mathrm{~g} / \mathrm{dL}$ for female and $<13 \mathrm{~g} / \mathrm{dL}$ for male patients). Accordingly, our iron-deficient patients were further subdivided into anemic and nonanemic groups where both male and female patients with hemoglobin $\leq 11 \mathrm{~g} / \mathrm{dL}$ were considered anemic.

\section{Inclusion Criteria for Controls}

All apparently healthy asymptomatic persons aged 14-80 years were included as controls provided that their hemoglobin was $>12 \mathrm{~g} / \mathrm{dL}, \mathrm{MCV}>80 \mathrm{fL}$, and serum ferritin $>20 \mathrm{ng} / \mathrm{mL}$. Also, they had to have no active ongoing infection and no history of hemolytic anemia, chronic diseases, infectious diseases, autoimmune diseases, immunosuppressant-drug intake, or hematinic intake in the preceding 3 months.

\section{Exclusion Criteria for Patients}

All patients with known or proven immunodeficiency, autoimmune diseases, chronic systemic illness, active infection or parasitic infestation, possible thalassemia traits, malignancies, protein- energy malnutrition, or other nutritional deficiencies are excluded. Those who had received IV iron or hematinic in the previous 3 months and those with a history of immunosuppressant-drug intake, chemotherapy, or radiotherapy were also excluded.

\section{Blood Sampling}

Venous blood samples were collected from patients and controls in EDTA tubes under aseptic conditions for processing. The samples were sent to the laboratory for complete blood counts, serum ferritin, serum iron, TIBC, and flow-cytometr $\mathrm{y}$ analysis for lymphocyte subsets. All samples of flow cytometry were taken and analyzed within 24 hours of collection. Complete blood counts were performed using an automated blood counter (Beckman Coulter). Serum ferritin was measured using an Architect ferritin-assay kit with chemiluminescent microparticle-immunoassay technology. Other iron profile parameters (serum iron and TIBC) were measured with a Dimension analyzer using spectrophotometry. Lymphocyte-subset enumeration was done using flow-cytometry analysis with a four-color panel FACSCalibur with CellQuest or MultiSet software. Lymphocytes were gated as CD45-positive cells with low sidescatter. B and T lymphocytes were separated using CD3 and CD19 markers. T-helper and cytotoxic T cells were separated using $\mathrm{CD} 4$ and $\mathrm{CD} 8$, where cells that were $\mathrm{CD} 3 / \mathrm{CD} 4^{+}$were considered T-helper cells and those that were $\mathrm{CD} 3 / \mathrm{CD} 8^{+}$considered cytotoxic T cells. Natural killer (NK) lymphocytes were identified using CD3-CD16 ${ }^{+}$and/or $\mathrm{CD}^{+} 6^{+}$cells. Percentage counts were calculated using CD45/side-scatter gating in which lymphocytes were showed bright CD45 and very little side-scatter. Absolute counts were determined by comparing cellular events to bead events automatically. 
Table I Demographic data

\begin{tabular}{|l|c|c|c|c|}
\hline \multirow{2}{*}{} & \multicolumn{2}{|c|}{ Iron-deficient patients } & \multicolumn{2}{c|}{ Controls } \\
\cline { 2 - 5 } & $\mathbf{n = 6 4}$ & $\%$ & n=19 & $\%$ \\
\hline Age, years & 6 & 9.4 & 0 & 0 \\
\hline $14-19$ & 14 & 21.9 & 1 & 5.3 \\
\hline $20-29$ & 21 & 32.8 & 13 & 68.4 \\
\hline $30-39$ & 17 & 26.6 & 2 & 10.5 \\
\hline $40-49$ & 4 & 6.3 & 3 & 15.8 \\
\hline $50-59$ & 2 & 3.1 & 0 & 0 \\
\hline$>60$ & 1 & 1.6 & 4 & 21.1 \\
\hline Sex & 63 & 98.4 & 15 & 78.9 \\
\hline Male & & & & \\
\hline Female & & & & \\
\hline
\end{tabular}

\section{Statistical Analysis}

The dependent variable was lymphocyte subsets change and the independent variables age, sex, hemoglobin level, serum-ferritin level, serum iron, and TIBC. Data were checked, entered, and analyzed using SPSS 25. Continuous variables are presented as means $\pm \mathrm{SD}$. Categorical variables are presented as numbers and percentages. Unpaired $t$-tests and $x^{2}$ tests were used to test for significant differences in hemoglobin level, MCV, platelet count, serum iron, TIBC, ferritin, and lymphocyte-subset indicators (changes) between the study groups. Logistic regression was used to estimate the risk of recurrent infection in relation to anemia and iron-deficiency indicators. All regression models were adjusted for sex and age. $p<0.05$ was considered statistically significant.

\section{Results}

\section{Demographic Data Analysis}

A total of 64 patients with who presented to hematology and family medicine clinics in our hospital with confirmed iron deficiency met the inclusion criteria (Table 1). Mean age was 35.66 \pm 12.11 (14-72) years. Patients were divided into anemic and nonanemic groups according to the World Health Organization definition of anemia (hemoglobin $<12 \mathrm{~g} / \mathrm{dL}$ for female patients and $13 \mathrm{~g} / \mathrm{dL}$ for male patients). In this study, both male and female patients with hemoglobin $\leq 11 \mathrm{~g} / \mathrm{dL}$ were considered anemic: $44(68.8 \%)$ met this criterion. Our controls comprised 19 apparently healthy adults fulfilling our inclusion criteria. The mean age of the controls wass $38.21 \pm 8.33$ (25-52) years Table 1).

\section{Descriptive Analysis}

Iron-deficient patients had significantly lower hemoglobin concentrations, $\mathrm{MCV}, \mathrm{MCH}$, serum ferritin, and serum iron than controls. On the other hand, iron-deficient patients had significantly higher TIBC than controls (Table 2). There was no statistically significant difference between patients and controls for platelet count $(p=0.215$, Table 2$)$.

No lymphocyte subsets showed statistically significant differences between iron-deficient patients (low ferritin) and controls (Table 3).

In Table 4, the studied lymphocyte-subset parameters in relation to hemoglobin levels among our iron-deficient patients are shown. Anemic patients tended to have significantly lower absolute lymphocyte counts than nonanemic ones. Also, there were statistically significant differences between anemic and nonanemic iron-deficient patients on relative T-cell counts, relative and absolute NK-cell counts and relative CD4-positive counts (Table 4). There were no statistically 
Table 2 Hematological parameters

\begin{tabular}{|c|c|c|c|c|c|}
\hline & \multicolumn{2}{|c|}{ Iron-deficient patients, $\mathrm{n}=64$} & \multicolumn{2}{|c|}{ Controls, $n=19$} & \multirow[t]{2}{*}{$p$} \\
\hline & Mean & SD & Mean & SD & \\
\hline $\mathrm{Hb}(\mathrm{g} / \mathrm{dL})$ & 9.69 & 1.87 & 12.34 & 2.18 & $<0.001$ \\
\hline MCV (fL) & 69.9 & 8.62 & 82.8 & 6.83 & $<0.001$ \\
\hline MCH (pg) & 22.13 & 3.56 & 27.32 & 2.95 & $<0.001$ \\
\hline Serum iron $(\mu \mathrm{g} / \mathrm{dL})$ & 32.34 & 27.07 & 59.05 & 41.71 & 0.001 \\
\hline TIBC $(\mu \mathrm{g} / \mathrm{dL})$ & 405.13 & 106.94 & 332.84 & 73.15 & 0.007 \\
\hline Ferritin (ng/mL) & 13.82 & 45.87 & 103.94 & 109.70 & $<0.001$ \\
\hline Platelets $\left(10^{3} / \mu \mathrm{L}\right)$ & 286.23 & 109.58 & 253.84 & 47.98 & 0.215 \\
\hline
\end{tabular}

Note: Bold font indicates statistical significance.

Table 3 Lymphocyte-subset parameters

\begin{tabular}{|c|c|c|c|c|c|}
\hline & \multicolumn{2}{|c|}{$\begin{array}{l}\text { Iron-deficient patients (low } \\
\text { ferritin), } n=64\end{array}$} & \multicolumn{2}{|c|}{ Controls, $n=19$} & \multirow[t]{2}{*}{$p$} \\
\hline & Mean & SD & Mean & SD & \\
\hline WBCs $\left(10^{3} / \mu L\right)$ & 6.37 & 2.63 & 6.62 & 3.18 & 0.738 \\
\hline Lymphocyte count $\left(10^{3} / \mu \mathrm{L}\right)$ & 3.205 & 11.61 & 2.757 & 10.21 & 0.133 \\
\hline T-cell \% & 74.32 & 7.46 & 75.05 & 4.94 & 0.690 \\
\hline T-cell absolute count (cells/ $\mu \mathrm{L}$ ) & $\mathrm{I}, 439.07$ & 483.38 & $\mathrm{I}, 352.97$ & 455.17 & 0.497 \\
\hline B-cell \% & 13.67 & 5 & 12.99 & 5.599 & 0.617 \\
\hline B-cell absolute count (cells/ $\mu \mathrm{L}$ ) & 271.06 & 141.37 & 236.24 & 124.20 & 0.336 \\
\hline NK-cell \% & 11.44 & 6.79 & 11.21 & 4.73 & 0.887 \\
\hline NK-cell absolute count (cells/ $\mu \mathrm{L})$ & 227.36 & 166.94 & 201.45 & 100.45 & 0.523 \\
\hline CD4\% & 44.01 & 6.80 & 43.59 & 6.37 & 0.812 \\
\hline CD4 absolute count (cells/pL) & 858.82 & 311.48 & 791.19 & 302.50 & 0.405 \\
\hline CD8\% & 29.56 & 7.47 & 30.08 & 6.69 & 0.788 \\
\hline CD8 absolute count (cells/ $\mu \mathrm{L}$ ) & 572.43 & 232 & 535.71 & 214.15 & 0.540 \\
\hline CD4:CD8 ratio & 1.62 & 0.60 & 1.57 & 0.69 & 0.770 \\
\hline
\end{tabular}

significant differences between anemic and nonanemic iron-deficient patients on B-cell counts, CD8-positive cell counts, or CD4:CD8 ratio (Table 4).

\section{Logistic Regression Results}

Finally, risk based on history of recurrent infections (two or more severe infections in 1 year or a need for antibiotics for 2 months/year) in relation to iron-deficiency indicators was estimated by logistic regression (Table 5). The results showed that with $\mathrm{Hb}<11 \mathrm{~g} / \mathrm{dL}$ the risk of having recurrent infections was significantly elevated (OR 2.55, CI 1.03-6.26; 
Table 4 Lymphocyte-subset parameters in relation to hemoglobin level among iron-deficient patients

\begin{tabular}{|c|c|c|c|c|c|}
\hline & \multicolumn{2}{|c|}{$\begin{array}{c}\text { Nonanemic }(\mathrm{Hb}>\mathrm{II} \mathrm{g} / \mathrm{dL}) \text { iron-deficient } \\
\text { patients, } \mathrm{n}=\mathbf{2 0}\end{array}$} & \multicolumn{2}{|c|}{$\begin{array}{c}\text { Anemic }(\mathrm{Hb} \leq \mathrm{I} \mathrm{I} / \mathrm{g} / \mathrm{d}) \text { iron-deficient } \\
\text { patients, } \mathrm{n}=44\end{array}$} & \multirow[t]{2}{*}{ p } \\
\hline & Mean & SD & Mean & SD & \\
\hline WBCs $\left(10^{3} / \mu L\right)$ & 5.47 & 1.56 & 6.78 & 2.92 & 0.064 \\
\hline Absolute lymphocyte count $\left(10^{3} / \mu \mathrm{L}\right)$ & 3.733 & 12.12 & 2.965 & 10.65 & 0.013 \\
\hline T-cell \% & 71.28 & 9.02 & 75.71 & 6.26 & 0.026 \\
\hline T-cell absolute count (cells/ $\mu \mathrm{L}$ ) & $1,498.91$ & 526.031 & $|, 4| \mid .88$ & 466.38 & 0.509 \\
\hline B-cell \% & 13.80 & 5.95 & $|3.6|$ & 4.58 & 0.890 \\
\hline B-cell absolute count (cells/ $\mu \mathrm{L}$ ) & 284.17 & 125.37 & 256.10 & 149.06 & 0.621 \\
\hline NK-cell \% & 14.24 & 9.26 & 10.17 & 4.94 & 0.025 \\
\hline 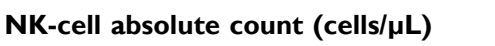 & 316.34 & 231.89 & 186.92 & 108.24 & 0.003 \\
\hline CD4\% & 40.18 & 7.15 & 45.75 & 5.93 & 0.002 \\
\hline 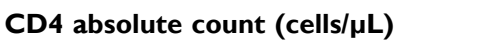 & 830.96 & 268.01 & 871.48 & 331.49 & 0.633 \\
\hline CD8\% & 29.86 & 8.03 & 29.43 & 7.30 & 0.836 \\
\hline 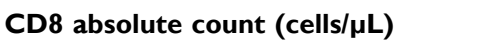 & 632.15 & 270.97 & 545.28 & 209.77 & 0.167 \\
\hline CD4:CD8 ratio & 1.48 & 0.64 & 1.68 & 0.58 & 0.213 \\
\hline
\end{tabular}

Note: Bold font indicates statistical significance.

Table 5 Risk based on history of recurrent infections in relation to iron-deficiency indicators on logistic regression

\begin{tabular}{|l|c|c|c|}
\hline \multirow{2}{*}{} & \multicolumn{3}{|c|}{ History of recurrent infections } \\
\cline { 2 - 4 } & OR & Cl & $p$ \\
\hline Hb $(\mathrm{g} / \mathrm{dL})$ & 2.55 & $1.03-6.26$ & 0.041 \\
\hline Serum ferritin $(\mathrm{ng} / \mathrm{mL})$ & 3.70 & $1.26-10.83$ & 0.01 \\
\hline Serum iron $(\mu \mathrm{g} / \mathrm{dL})$ & 0.38 & $0.14-1.03$ & 0.059 \\
\hline TIBC $(\mu \mathrm{g} / \mathrm{dL})$ & 0.912 & $0.32-2.59$ & 0.86 \\
\hline
\end{tabular}

Notes: Bold font indicates statistical significance.

$p=0.041$ ), as well as for ferritin $<20 \mathrm{ng} / \mathrm{mL}$ (OR 3.70 , CI $1.26-10.83 ; p=0.01$ ). However, there were no significantly elevated risks associated with history of recurrent infections with decreased serum-iron or increased TIBC levels.

\section{Discussion}

It is well known that women of reproductive age and children are more prone to iron-deficiency anemia. Iron is considered an important element not only for DNA synthesis and RBC formation but also for immune-system integrity. ${ }^{11-13}$ As we know, peripheral lymphocytes play an important role in the body's defenses against infections. The mechanism by which iron deficiency affects these lymphocytes is not well understood. To investigate the important role of iron deficiency and its effects on immunity, this study analyzed the distribution of lymphocyte subsets and their correlations with iron-deficiency indicators, ie, hemoglobin, serum ferritin, serum iron, and TIBC. 
There were statistically significant differences in absolute lymphocyte, relative T-cell, relative $\mathrm{CD}^{+}{ }^{+}$, relative NKcell, and absolute counts between anemic $(\mathrm{Hb} \leq 11 \mathrm{~g} / \mathrm{dL})$ and nonanemic iron-deficient patients. Absolute lymphocyte counts in anemic patients were significantly lower than nonanemic ones $(p=0.013)$. This is similar to the results of previous studies. ${ }^{14-17}$ Also, relative T-cell counts were significantly higher in anemic than nonanemic patients $(p=0.026)$. This finding is consistent with the results of Sejas et al, Attia et al, and Berger et al. ${ }^{5,18,19}$ van Heerden et al discovered that T-cell proliferation was higher among iron-deficient patients. ${ }^{20}$ This finding was confirmed by Attia et al, who found that there was an increase in immature T-cell marker CD1a in iron-deficient patients. ${ }^{19}$ In our results, relative CD4positive cell counts showed statistically significant differences between anemic and nonanemic patients $(p=0.002)$. Both relative NK-cell and absolute counts were significantly lower in anemic patients than nonanemic ones. To the best of our knowledge, no study has highlighted changes in NK cells in relation to Hb-level changes in humans. Sherman et al and Spear et al studied this relationship only in rats fed iron-depleted food. Both studies highlighted impairment of NK-cell function (cytotoxicity killing power), rather than count. ${ }^{21,22}$

Differences in means of lymphocyte-subset parameter between patients and controls were not statistically significant. These results are consistent with Ekiz et al, Mohri et al, and Thibault et al who reported that no statistically significant differences in lymphocyte subsets between patients with low ferritin and controls. ${ }^{6,23,24}$ Our results showed no statistically significant difference in lymphocyte subsets between patients with low serum iron and patients with normal serum iron. There were no statistically significant differences between anemic and nonanemic iron-deficient patients in relative or absolute B-cell counts ( $p=0.89$ and $p=0.621$, respectively). These results matched those of Beard et al, who concluded that B cells (arm of humoral immunity) seemed less likely to affected by iron deficiency than T cells (arm of cell-mediated immunity). ${ }^{25}$

In this study, it was quite obvious that the changes in lymphocyte subsets started mainly in response to decreased hemoglobin levels, rather than decreased ferritin and/or iron levels. The decreased hemoglobin led to absolute decreases in total lymphocytes and NK cells and a relative increase in $\mathrm{CD}^{+}$T-helper cells. Synchronously, increased TIBC levels leads to an absolute decrease in NK cells and relative increase in T cells. B cells were not affected by any of the iron-deficiency indicators. To our knowledge, no studies have highlighted the risk of recurrent infections in irondeficiency anemia in adults. Therefore, it was interesting to investigate the relationships between the risk associated with a history of recurrent infections and iron-deficiency indicators in this study. Our results showed that there was a statistically significant increase in risk associated with a history of recurrent infections among iron-deficient patients with decreased $\mathrm{Hb}$ and/or ferritin levels. In addition, upper respiratory tract and urinary tract infections were the most common infections reported by the iron-deficient patients.

\section{Recommendations}

1. Future studies with larger samples and higher proportion of male sex would be more informative.

2. Studying the effect of iron deficiency on lymphocyte subsets in pediatric age-groups would be extremely beneficial.

3. For all iron-deficiency anemia patients, monitoring lymphocyte-subset changes may predict the risk of recurrent infections.

4. Further similar studies are recommended to explore changes in lymphocyte subsets in relation to anemia other than iron deficiency, particularly for those patients with anemia of chronic diseases.

\section{Conclusion}

Iron deficiency has an obvious effect on lymphocyte subsets. Among iron-deficiency indicators, decreased hemoglobin level seems to be the driving force that initiates changes in lymphocyte subsets, rather than decreased ferritin and/or iron levels. Generally, synchronously decreased hemoglobin levels led to absolute decreases in total lymphocytes, mainly NK cells, and relative increases in T cells, mainly the helper ones. Meanwhile, B cells were not affected by any of the irondeficiency indicators. Furthermore, there was a three- to fourfold increase in risk of recurrent infections among patients with iron-deficiency anemia. 


\section{Acknowledgment}

The Authors appreciate all efforts made by everyone who contributed to this study; Dr. Hanan AlDuailej, Sawsan AlMatroud, Rana AlYousef, short stay ward (1C) staff, and Hematology Laboratory staff.

\section{Disclosure}

The authors report no conflicts of interest in this work.

\section{References}

1. Chandra RK. Nutrition and the immune system from birth to old age. Eur J Clin Nutr. 2002;56(Suppl 3):S73-S76. doi:10.1038/sj.ejen.1601492

2. Hall A, Bobrow E, Brooker S, et al. Anaemia in schoolchildren in eight countries in Africa and Asia. Public Health Nutr. 2001;4(3):749-756. doi:10.1079/PHN2000111

3. Collins HL, Kaufmann SH, Schaible UE. Iron chelation via deferoxamine exacerbates experimental salmonellosis via inhibition of the nicotinamide adenine dinucleotide phosphate oxidase-dependent respiratory burst. J Immunol. 2002;168(7):3458-3463. doi:10.4049/jimmunol.168.7.3458

4. Omara FO, Blakley BR. The effects of iron deficiency and iron overload on cell-mediated immunity in the mouse. Br J Nutr. 1994;72(6):899-909. doi:10.1079/BJN19940094

5. Sejas E, Kolsteren P, Hoeree T, Roberfroid D. Iron supplementation in previously anemic Bolivian children normalized hematologic parameters, but not immunologic parameters. J Trop Pediatr. 2008;54(3):164-168. doi:10.1093/tropej/fmm106

6. Ekiz C, Agaoglu L, Karakas Z, Gurel N, Yalcin I. The effect of iron deficiency anemia on the function of the immune system. Haematol J. 2005;5 (7):579-583. doi:10.1038/sj.thj.6200574

7. Tang YM, Chen XZ, Li GR, Zhou RH, Ning H, Yan H. [Effects of iron deficiency anemia on immunity and infectious disease in pregnant women]. Wei Sheng Yan Jiu. 2006;35(1):79-81. Chinese.

8. Schaible UE, Kaufmann SH. Iron and microbial infection. Nat Rev Microbiol. 2004;2(12):946. doi:10.1038/nrmicro1046

9. Mast AE, Blinder MA, Gronowski AM, Chumley C, Scott MG. Clinical utility of the soluble transferrin receptor and comparison with serum ferritin in several populations. Clin Chem. 1998;44(1):45-51. doi:10.1093/clinchem/44.1.45

10. Soppi ET. Iron deficiency without anemia - a clinical challenge. Clin Case Rep. 2018;6(6):1082-1086. doi:10.1002/ccr3.1529

11. Bhaskaram P. Micronutrient malnutrition, infection, and immunity: an overview. Nutr Rev. 2002;60(5 Pt 2):S40-S45. doi:10.1301/ 00296640260130722

12. Vydyborets SV. [An analysis of the immunity indices of patients with iron-deficiency anemia]. Lik Sprava. 2000;3-4:71-75. Ukrainian.

13. Soyano A, Gomez M. [Role of iron in immunity and its relation with infections]. Arch Latinoam Nutr. 1999;49(3Suppl 2):40S-6S. Spanish.

14. Aly SS, Fayed HM, Ismail AM, Abdel Hakeem GL. Assessment of peripheral blood lymphocyte subsets in children with iron deficiency anemia BMC Pediatr. 2018;18(1):49. doi:10.1186/s12887-018-0990-5

15. Özcan A, Çakmak M, Toraman AR, et al. Evaluation of leucocyte and its subgroups in iron deficiency anemia. Int J Med Med Sci. 2011;3 (5):135-138

16. Mullick S, Rusia U, Sikka M, Faridi MA. Impact of iron deficiency anaemia on T lymphocytes \& their subsets in children. Indian J Med Res. 2006;124(6):647-654.

17. Santos PC, Falcao RP. Decreased lymphocyte subsets and K-cell activity in iron deficiency anemia. Acta Haematol. 1990;84(3):118-121. doi: $10.1159 / 000205047$

18. Berger J, Schneider D, Dyck J-L, et al. Iron deficiency, cell-mediated immunity and infection among 6-36 month old children living in rural Togo. Nutr Res. 1992;12(1):39-49. doi:10.1016/S0271-5317(05)80408-7

19. Attia MA, Essa SA, Nosair NA, Amin AM, El-Agamy OA. Effect of iron deficiency anemia and its treatment on cell mediated immunity. Indian $J$ Hematol Blood Transfus. 2009;25(2):70-77. doi:10.1007/s12288-009-0017-3

20. van Heerden R. Evaluation of neutrophil and lymphocyte function in subjects with iron deficiency. S Afr Med J. 1981;59(4):111-113.

21. Sherman AR, Lockwood JF. Impaired natural killer cell activity in iron-deficient rat pups. J Nutr. 1987;117(3):567-571. doi:10.1093/jn/117.3.567

22. Spear AT, Sherman AR. Iron deficiency alters DMBA-induced tumor burden and natural killer cell cytotoxicity in rats. $J$ Nutr. 1992;122(1):46-55. doi:10.1093/jn/122.1.46

23. Bami MH, Mohri M, Seifi HA, Tabatabaee AA. Effects of parenteral supply of iron and copper on hematology, weight gain, and health in neonatal dairy calves. Vet Res Commun. 2008;32(7):553-561. doi:10.1007/s11259-008-9058-6

24. Thibault H, Galan P, Selz F, et al. The immune response in iron-deficient young children: effect of iron supplementation on cell-mediated immunity. Eur J Pediatr. 1993;152(2):120-124. doi:10.1007/BF02072487

25. Beard JL. Iron biology in immune function, muscle metabolism and neuronal functioning. $J$ Nutr. 2001;131(2s-2):568S-79S; discussion 80S. doi:10.1093/jn/131.2.568S

Journal of Blood Medicine

Dovepress

\section{Publish your work in this journal}

The Journal of Blood Medicine is an international, peer-reviewed, open access, online journal publishing laboratory, experimental and clinical aspects of all aspect pertaining to blood based medicine including but not limited to: Transfusion Medicine; Blood collection, Donor issues, Transmittable diseases, and Blood banking logistics; Immunohematology; Artificial and alternative blood based therapeutics; Hematology; Biotechnology/nanotechnology of blood related medicine; Legal aspects of blood medicine; Historical perspectives. The manuscript management system is completely online and includes a very quick and fair peer-review system. Visit http://www.dovepress.com/testimonials.php to read real quotes from published authors.

Submit your manuscript here: http://www.dovepress.com/journal-of-blood-medicine-journal 